\title{
Intra-individual variability in day-to-day and month-to-month measurements of physical activity and sedentary behaviour at work and in leisure-time among Danish adults
}

\author{
E. S. L. Pedersen, I. H. Danquah, C. B. Petersen and J. S. Tolstrup*
}

\begin{abstract}
Background: Accelerometers can obtain precise measurements of movements during the day. However, the individual activity pattern varies from day-to-day and there is limited evidence on measurement days needed to obtain sufficient reliability. The aim of this study was to examine variability in accelerometer derived data on sedentary behaviour and physical activity at work and in leisure-time during week days among Danish office employees.

Methods: We included control participants $(n=135)$ from the Take a Stand! Intervention; a cluster randomized controlled trial conducted in 19 offices. Sitting time and physical activity were measured using an ActiGraph GT3X+ fixed on the thigh and data were processed using Acti4 software. Variability was examined for sitting time, standing time, steps and time spent in moderate-to-vigorous physical activity (MVPA) per day by multilevel mixed linear regression modelling.

Results: Results of this study showed that the number of days needed to obtain a reliability of $80 \%$ when measuring sitting time was 4.7 days for work and 5.5 days for leisure time. For physical activity at work, 4.0 days and 4.2 days were required to measure steps and MVPA, respectively. During leisure time, more monitoring time was needed to reliably estimate physical activity ( 6.8 days for steps and 5.8 days for MVPA).

Conclusions: The number of measurement days needed to reliably estimate activity patterns was greater for leisure time than for work time. The domain specific variability is of great importance to researchers and health promotion workers planning to use objective measures of sedentary behaviour and physical activity.
\end{abstract}

Trial registration: Clinical trials NCT01996176.

Keywords: Variability, Reliability, Accelerometer, Sedentary behaviour, Physical activity

\section{Background}

Sedentary behaviour and physical inactivity have been associated with risk of adverse health outcomes and higher mortality [1-4]. In modern society, many people have office-based jobs entailing many hours of sitting [5] and hours spent sitting at work seems to be increasing [6]. Thus, occupational sitting has been the subject for much research interest lately [7]. To assess risks associated with sedentary behaviour at work and in leisure time, and due to the limitations of self-reported measures, there has recently been an increase in using

\footnotetext{
* Correspondence: jst@niph.dk

National Institute of Public Health, University of Southern Denmark, Øster Farimagsgade 5A, 2. Floor, 1353 Copenhagen, Denmark
}

accelerometers to assess sitting time, even in large population based studies. The degree to which such measurements express the true mean of an individual's activity pattern (including both sedentary behaviour and physical activity) depends on the day-to-day and over time variability in the activity pattern. The more the activity pattern varies, the more days of monitoring are needed. In order to obtain reliable results and also keep participation burden to a minimum, an important aspect of accelerometer measurements is how many days of measurement are needed to obtain reliable estimates of sedentary behaviour and physical activity.

Several studies have examined the day-to-day variability in activity patterns in adults and found that the monitoring 
frame needed to reliably assess daily physical activity ranged between 3 and 16 days [8-13]. However, only few of these studies have analysed reliability for physical activity and sedentary behaviour separately and have shown opposing findings [11-13]. Further, little is known of the difference in the variability of the activity pattern at work compared to leisure time. Previously, in a study using self-reported measures, it has been shown that fewer days are needed for measuring physical activity at work (14-21 days) versus in leisure time (21-28 days) [11]. However, using objective measures, so far no studies have examined the intra-individual variability during work and leisure time, separately.

In the cluster randomized controlled trial, Take a Stand!, repeated measurements of activity were obtained via accelerometry to evaluate the effect of a multicomponent intervention among office workers on sitting time [13]. The control group comprised a perfect population for studying variability in sedentary behaviour and physical activity among office employees on weekdays.

The aim of this study was to examine the day-to-day and month-to-month variability in sedentary behaviour and physical activity during weekdays at work and leisure time in office working adults and to identify number of days needed for capturing reliable estimates of habitual physical activity and sedentary behaviour.

\section{Methods}

\section{Study design}

This study uses data from participants who were assigned to the control group $(n=135)$ in the Take a Stand!-trial, where accelerometer-derived measures were obtained at baseline and after 1 and 3 months.

Take a Stand! was a cluster randomized controlled trial conducted in 19 offices (clusters) in four workplaces in Denmark and Greenland from November 2013 to June 2014 aiming to reduce sitting time among office workers. The methods and primary outcomes from Take a Stand! are described in detail elsewhere [14]. In short, half of the included clusters were exposed to the intervention and the other half were included as controls. Because of the cluster design of Take a Stand! participants were recruited through their workplaces. Employees were invited by e-mail to participate, were informed of the project in writing and orally and signed informed consent forms. Eligible workplaces were officebased with employees who sat most of the workday. All participants had sit-stand desks prior to inclusion. Eligible individuals were $\geq 18$ years, understood Danish and worked more than 4 days a week ( $>30 \mathrm{~h})$. Exclusion criteria were sickness or disabilities affecting the ability to stand or walk, and pregnancy. Mean age was 46 years and three quarters were female $(74 \%)$, which was representative of the population at the participating workplaces. Information on work environment, sociodemographic factors, health status, and health behaviour was collected by a web-based questionnaire and physical activity and sedentary behaviour were measured objectively by an accelerometer at baseline and repeated at $1^{\text {st }}$ follow-up after one month and at $2^{\text {nd }}$ follow-up after three months. The descriptive characteristics of the study sample are shown in Table 1 . The trial was approved by the local Ethics Committee in Denmark (H-6-2013-005) and in Greenland (project 20914-3, id: 2014-095402) and was prospectively registered at Clinicaltrials.gov (NCT01996176). Procedures were designed in accordance with the Helsinki Declaration.

\section{Measurement of physical activity and sedentary behaviour} Variability in physical activity and sedentary behaviour was examined through daily means of the following variables: mean sitting time per day, mean standing time per day, mean steps per day and mean time spent in MVPA (total of walking fast, climbing stairs, running, cycling and rowing).

Participants wore an ActiGraph GT3X+ accelerometer, which records tri-axial accelerations and was set to record with $30 \mathrm{~Hz}$ [15]. The device is waterproof and was fixed with tape on the front of the thigh midway between the hip and knee joint. Participants wore the device $24 \mathrm{~h}$ a day and it was attached to each participant during working hours on Monday and removed after work on Friday. The accelerometer was removed only in case of prolonged water activities $(>30 \mathrm{~min})$, contact sport or skin irritation. Participants kept a log during the accelerometer period, where they recorded sleep, working hours and any irregularities or problems with the accelerometer. Data were only collected on weekdays

Table 1 Population characteristics $(n=153)$

\begin{tabular}{|c|c|c|}
\hline & Number & Percent \\
\hline \multicolumn{3}{|l|}{ Demographic factors } \\
\hline Age (years, mean [SD]) & 46 & $(11)$ \\
\hline Females & 100 & (74) \\
\hline Married/living together & 111 & (82) \\
\hline Tertiary education & 80 & (59) \\
\hline \multicolumn{3}{|l|}{ Health and health behaviour } \\
\hline BMI (mean [SD]) & 26 & (5) \\
\hline Overweight (BMI > 25) & 96 & (58) \\
\hline Daily smoking & 23 & $(17)$ \\
\hline \multicolumn{3}{|l|}{ Self-rated health } \\
\hline Excellent/very good/Good & 126 & (93) \\
\hline \multicolumn{3}{|l|}{ Self-rated fitness } \\
\hline Very good/good & 49 & $(37)$ \\
\hline
\end{tabular}


because Take a Stand! was designed to evaluate the effect of the intervention during working hours.

Accelerometer data were processed using Acti4 software, specifically developed for thigh placement of the Actigraph [16]. Acti4 data processing has been validated in different settings, e.g. for sitting time during free living; Skotte et al. [16] found sensitivity to be $98.2 \%$ and specificity $93.3 \%$, similar results have been found elsewhere [16-18]. Acti4 uses information on accelerometry and inclinometry to compile total minutes spent sitting/ reclining, standing, walking, climbing stairs, running, cycling and rowing and all activities are thus defined as a combination of these. Activities were analysed with a minimum bout length of $15 \mathrm{~s}$. for rowing and cycling, $5 \mathrm{~s}$. for stair walking, sitting and lying and $2 \mathrm{~s}$. for running, walking, moving and standing. As mentioned above MVPA was the total time spent walking fast, climbing stairs, running, cycling and rowing.

Time at work, during leisure time and sleep were distinguished using the information recorded in the log. Data was summed for a 24-h period, starting with work in the morning and ending with leisure time in the morning on the following day, in this way we accounted for the missing leisure time periods due to accelerometer mounting during working hours. This meant that working hours on Friday was not included in the analyses. During this 24-h period, time spent working (at the workplace or at home) was summed, equally all leisure time was summed. To be able to compare between the different days and months, work time and leisure time were standardized to eight hours per day. Eligible days included at least $4 \mathrm{~h}$ of work. Non-wear time was identified in three ways and data from those times were discarded, including a buffer of 10 min before and after: 1) if reported in the log; 2) if detected manually during data processing; or 3) if detected by Acti4 (a combination of $>60$ min with no movement immediately preceded by strong acceleration) [16]. Only days with complete data on work and leisure time were included. If a day was excluded, the remaining included days kept their numbering in the weekly sequence to ensure that possible variance due to reactivity of wearing the accelerometer at day 1 or day-specific work/leisure structures would not disappear by mixing up the days.

\section{Statistical analyses}

To estimate the variability in the accelerometer-derived data, random effect models were analysed using multilevel mixed linear regression. The dependent variable was the accelerometer output of interest (e.g. sitting time). Inter-individual variance (reflecting variance between clusters and between individuals) and intraindividual (residual) variance were estimated and intraclass correlation coefficients (ICC) were calculated as between subject variance/ (between subject variance + residual variance). Generally, an ICC of 0.80 is considered acceptable reliability [19]. Relative standard deviation (RSD) was estimated for the purpose of comparing total variance of the different activity variables between work time and leisure time and it was calculated as: RSD $=\frac{\sqrt{\sigma}}{\mu}$, where $\sigma$ represented total variance and $\mu$ represented the mean (the constant from the regression output). Differences in variance between days and between months were estimated using likelihood ratio test comparing the full model with a model where day or month, respectively, was taken out of the model.

In order to determine the number of days needed to estimate mean sitting, standing, steps and MVPA all measurement days were combined from the three periods. Then The Spearman-Brown prophecy formula based on ICC was used to determine the number of days needed to represent each activity during working hours and during leisure time. The formula was as follows: $\mathrm{N}=[\mathrm{ICCd}$ (1ICCd) ${ }^{*}[(1-\mathrm{ICCe}) / \mathrm{ICCe}]$, where $\mathrm{N}=$ number of days needed, $\mathrm{ICCd}=$ desired level of reliability $(0.80,0.85$ or $0.90)$ and $\mathrm{ICCe}=$ estimated level of reliability $[20,21]$.

Analyses were done for work time and leisure time, separately. Analyses were conducted using STATA/IC-14.0.

\section{Results}

Table 2 shows the number of days wearing the Actigraph and the mean wear time at work and during leisure time at each of the months of measurements. Mean number

Table 2 Wear time of ActiGraph accelerometer at day 1-4 of each of the three measurement months by work and leisure time

\begin{tabular}{|c|c|c|c|}
\hline & $\begin{array}{l}\text { Month } 1 \\
(n=132)\end{array}$ & $\begin{array}{l}\text { Month } 2 \\
(n=119)\end{array}$ & $\begin{array}{l}\text { Month } 3 \\
(n=111)\end{array}$ \\
\hline & Mean (SD) & Mean (SD) & Mean (SD) \\
\hline No. of wearing days & $3.2(0.8)$ & $3.5(0.8)$ & $3.1(0.9)$ \\
\hline Median (IQR) & $3(3 ; 4)$ & $4(3 ; 4)$ & $3(3 ; 4)$ \\
\hline \multicolumn{4}{|l|}{ Work-hour, min/day } \\
\hline Day 1 & $381(90)$ & 429 (99) & $414(92)$ \\
\hline Day 2 & $456(56)$ & $459(68)$ & $452(62)$ \\
\hline Day 3 & $454(65)$ & $458(69)$ & $467(78)$ \\
\hline Day 4 & $487(85)$ & $502(71)$ & $473(91)$ \\
\hline Mean & $446(50)$ & $458(51)$ & $447(56)$ \\
\hline \multicolumn{4}{|l|}{ Leisure-time, min/day } \\
\hline Day 1 & $448(88)$ & $486(103)$ & $475(91)$ \\
\hline Day 2 & $518(81)$ & $525(92)$ & $541(88)$ \\
\hline Day 3 & $527(100)$ & $519(91)$ & $518(108)$ \\
\hline Day 4 & $490(94)$ & $475(89)$ & $505(120)$ \\
\hline Mean & $502(66)$ & $503(67)$ & $514(78)$ \\
\hline
\end{tabular}


of wearing days was a little higher in the second month (3.5 wearing days) compared to the first month and the third month (3.2 and 3.1 wearing days, respectively). Time spent at work varied little between the three months with a mean ranging from $446 \mathrm{~min} /$ day (Standard deviation $(\mathrm{SD})=50)$ to $458 \mathrm{~min} /$ day $(\mathrm{SD}=51)$. At every measurement day and for every measurement month, participants had slightly more leisure time than working time. Generally, for both work and leisure time, wear time was lower at day 1 (where the accelerometer was put on during working hours) compared to other days.

Mean time spent on sedentary behaviour and physical activity during work and leisure time by single days of measurement and by the three measurement months are shown in Table 3. Results showed no significant difference in the mean minutes/per day measured from dayto-day during work and leisure time for any of the included sedentary behaviour and physical activity variables. Also, the differences in mean minutes/day measured from month-to-month were small, although the differences were statistically different for sitting and standing during both working hours and leisure time and also for MVPA in leisure time and mean steps per day at work (Fig. 1)

Variance components (inter- and intra-individual) are shown in Table 4. Overall, the variation in sitting time did not seem to differ between work and leisure time, whereas the variation in standing time was greater at work $(\mathrm{RSD}=0.62)$ compared to during leisure time $(\mathrm{RSD}=0.38)$. The variation in mean steps per day and time spent on MVPA, however, was greater during leisure time compared to at work. The inter-individual variability in the activity pattern was mainly explained by variability between individuals more than between clusters. The variance explained by the difference between clusters only had an influence on physical activity at work; mean steps per day comprised $12 \%$ of the total variance and MVPA comprised 11\% (data not shown). The intra-individual variability in all included activityvariables was smaller at work (50-54\%) than during leisure time (54-63\%).

Number of measurement days needed to estimate sedentary behaviour and physical activity is shown in Table 5. The number of measurement days needed to obtain $80 \%$ reliability ranged between 4.0 for steps per day to 4.7 days for sitting time. More days were needed to reliably estimate sedentary behaviour and physical activity during leisure time, ranging from 4.7 for standing time to 6.8 days for total steps. When time was not divided into working hours and leisure time, fewer days were needed to obtain $80 \%$ reliability, ranging from 3.0 days for standing time to 5.3 days for total steps.

\section{Discussion}

In this study, we found no variation in day-to-day measurement of activity but small differences were observed for month-to-month measurements. Results suggest that during working hours, 4.7 days are needed to reliably estimate sitting time. Less monitoring time is needed for measuring physical activity at work (4.0 days for steps and 4.2 days for MVPA). During leisure time, 5.5 days are needed for estimating sitting time while more monitoring time is needed to reliably estimate physical activity ( 6.8 days for steps and 5.8 days for MVPA).

Although, previous findings vary somewhat between studies $[8,9,11,13,21]$, most evidence suggest that a reliable estimate of sedentary behaviour and physical activity using an accelerometer is achieved with 3-7 days of monitoring over a single period. This is in line with the findings in the present study. Our results add to the current literature showing that the day-to-day variability of sedentary behaviour and physical activity was greater during leisure time compared to during working hours. Thus, more days are needed to obtain reliable estimates for leisure time than working hours and also more days are needed to study these two domains separately compared to total time. The difference in reliability for measurements of worktime and leisure time physical activity is important for studies focusing on health effects of domain-specific physical activity. Studies show that associations between physical activity and all-cause mortality differ between domains (work, sports, household, leisure) [22-24]. Activity was measured using questionnaires but for more valid results, physical activity should be measured using objective measures. For the purpose of designing studies like these, it is important to consider that activity patterns vary across domains and that different numbers of measurement days are needed to get reliable estimates of sedentary behaviour and physical activity, which the results of the present study show.

Activities that are less predictable on a day-to-day basis require more monitoring days to reliably predict behaviour. In the current study, we observed several important activity-specific differences. For leisure and work combined, less variability was seen for sitting and standing (3-4 days of measuring were needed for $80 \%$ reliability) compared to total steps and MVPA (requiring more than 5 days of measuring for $80 \%$ reliability). This finding is in contrast with other findings where sedentary behaviour needed more days of measuring compared to MVPA [11, 25]. In these studies, however, the populations differed in regard to age and demographics, which indicates that variability in activity depends on the characteristics of the population. Furthermore, in the present study, when separating work and leisure time, the opposite patterns of variability in activity was found for work where more days were needed to measure sitting 
Table 3 Minutes spent sitting, standing and in moderate-to-vigorous physical activity (MVPA) per day and steps per day during work and in leisure time at day $1-4$ for month 1,2 and 3. ( $n=$ number of participants with valid accelerometer information on the particular day)

\begin{tabular}{|c|c|c|c|c|c|c|c|}
\hline & \multicolumn{2}{|c|}{ Month 1} & \multicolumn{2}{|c|}{ Month 2} & \multicolumn{2}{|c|}{ Month 3} & \multirow[t]{2}{*}{$p$-value day ${ }^{a}$} \\
\hline & $n$ & Mean (SD) & $n$ & Mean (SD) & $n$ & Mean (SD) & \\
\hline Work sit & & & & & & & 0.700 \\
\hline Day 1 & 83 & 326 (83) & 112 & 359 (69) & 90 & $356(74)$ & \\
\hline Day 2 & 127 & 341 (62) & 116 & 345 (83) & 107 & 352 (82) & \\
\hline Day 3 & 124 & 345 (69) & 105 & 351 (71) & 94 & 356 (71) & \\
\hline Day 4 & 93 & $328(91)$ & 87 & 376 (54) & 52 & 342 (89) & \\
\hline Work stand & & & & & & & 0.656 \\
\hline Day 1 & 83 & $101(72)$ & 112 & $77(60)$ & 90 & $80(61)$ & \\
\hline Day 2 & 127 & $89(53)$ & 116 & $90(72)$ & 107 & $82(70)$ & \\
\hline Day 3 & 124 & $87(58)$ & 105 & $84(61)$ & 94 & 76 (59) & \\
\hline Day 4 & 93 & 103 (79) & 87 & $61(40)$ & 52 & $87(12)$ & \\
\hline Work steps & & & & & & & 0.262 \\
\hline Day 1 & 83 & 3716 (1499) & 112 & 3316 (1608) & 90 & 3247 (1391) & \\
\hline Day 2 & 127 & 3604 (1432) & 116 & 3271 (1487) & 107 & 3404 (1665) & \\
\hline Day 3 & 124 & 3411 (1543) & 105 & 3279 (1421) & 94 & 3478 (1393) & \\
\hline Day 4 & 93 & 3293 (1355) & 87 & 3162 (1507) & 52 & 3740 (1717) & \\
\hline Work MVPA & & & & & & & 0.314 \\
\hline Day 1 & 83 & $22(11)$ & 112 & $22(12)$ & 90 & $22(11)$ & \\
\hline Day 2 & 127 & $26(11)$ & 116 & $24(12)$ & 107 & $25(14)$ & \\
\hline Day 3 & 124 & $24(11)$ & 105 & $23(11)$ & 94 & $25(11)$ & \\
\hline Day 4 & 93 & $24(11)$ & 87 & $25(12)$ & 52 & $28(14)$ & \\
\hline Leisure sit & & & & & & & 0.360 \\
\hline Day 1 & 83 & $282(63)$ & 112 & 291 (58) & 90 & 284 (58) & \\
\hline Day 2 & 127 & 279 (59) & 116 & 287 (58) & 107 & 278 (63) & \\
\hline Day 3 & 124 & $285(56)$ & 105 & 293 (59) & 94 & 276 (65) & \\
\hline Day 4 & 93 & 301 (59) & 87 & 292 (67) & 52 & $272(71)$ & \\
\hline Leisure Stand & & & & & & & 0.382 \\
\hline Day 1 & 83 & $100(35)$ & 112 & $99(38)$ & 90 & $103(35)$ & \\
\hline Day 2 & 127 & $105(35)$ & 116 & $102(39)$ & 107 & 107 (38) & \\
\hline Day 3 & 124 & $103(37)$ & 105 & $99(36)$ & 94 & $106(40)$ & \\
\hline Day 4 & 93 & $94(34)$ & 87 & $100(41)$ & 52 & $108(41)$ & \\
\hline Leisure steps & & & & & & & 0.780 \\
\hline Day 1 & 83 & $5900(2986)$ & 112 & 5361 (2646) & 90 & 5555 (2623) & \\
\hline Day 2 & 127 & 5770 (2730) & 116 & 5433 (2669) & 107 & $5542(2533)$ & \\
\hline Day 3 & 124 & 5669 (2634) & 105 & 5362 (2823) & 94 & 5932 (2919) & \\
\hline Day 4 & 93 & 5065 (2230) & 87 & $5253(2555)$ & 52 & 6407 (3637) & \\
\hline Leisure MVPA & & & & & & & 0.293 \\
\hline Day 1 & 83 & $45(25)$ & 112 & $43(28)$ & 90 & $44(24)$ & \\
\hline Day 2 & 127 & $51(29)$ & 116 & $47(27)$ & 107 & $50(29)$ & \\
\hline Day 3 & 124 & $48(28)$ & 105 & $44(26)$ & 94 & $52(32)$ & \\
\hline Day 4 & 93 & $40(22)$ & 87 & $40(25)$ & 52 & $49(28)$ & \\
\hline
\end{tabular}

aLikelihood ratio test for equal means between days 


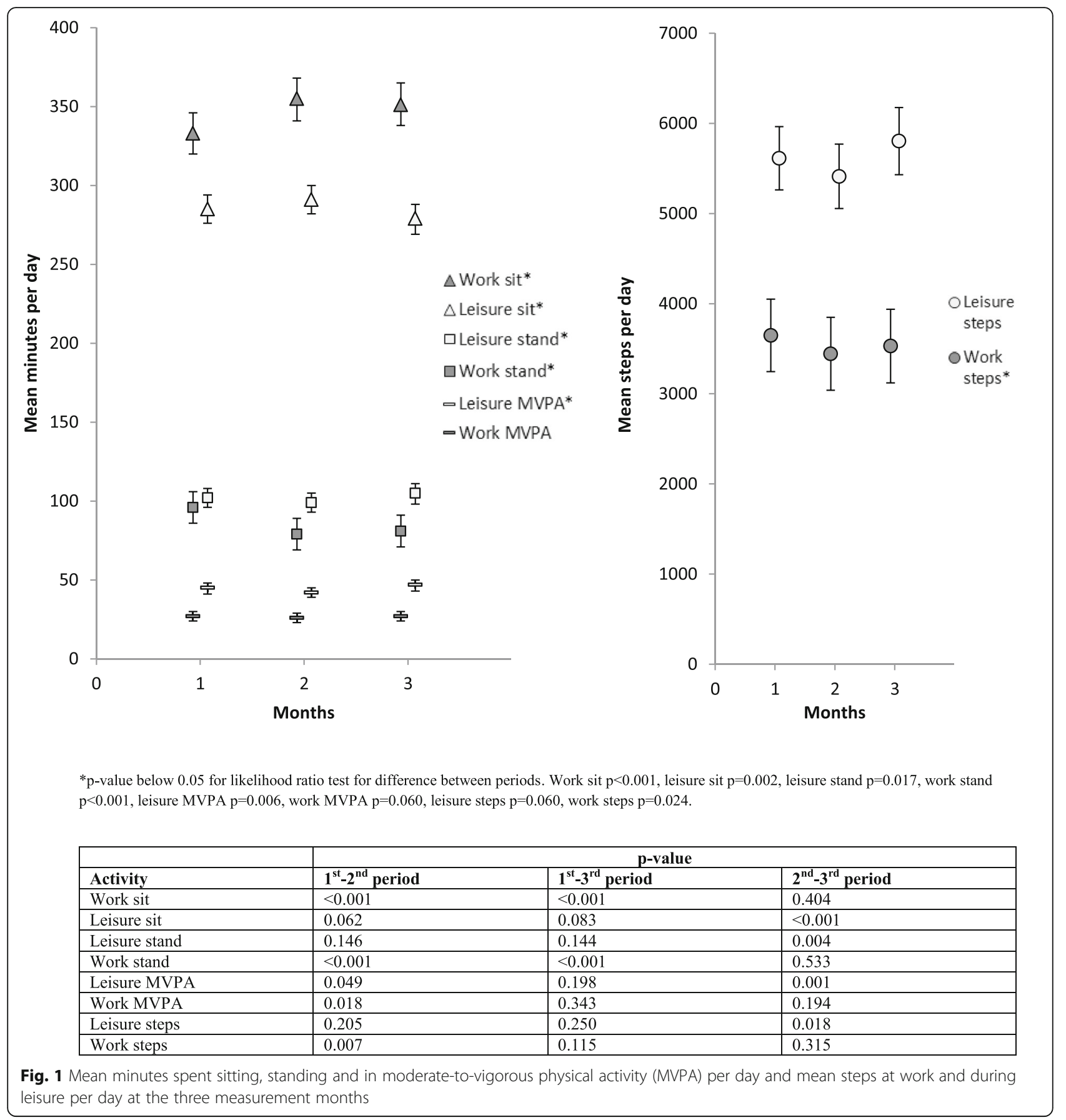

and standing compared to steps and MVPA. This emphasizes the importance of considering type of activity as well as domain when measuring physical activity and sedentary behaviour. The contrasting domain-specific findings are in agreement with previous studies in which some have indicated that more days are needed when measuring sedentary behaviour compared to physical activity $[13,24]$ while others have shown the opposite $[10,12]$. In line with this, it is important to be aware that variation might be different for other outcomes than the ones described in the present study (e.g. vigorous activity or sedentary behaviour defined in another way).

In the current study, we did not observe day-to-day variability, which in part could be due to the structure of the days for the participants. They all had desk-based jobs which entailed little movement during the day and job tasks did not vary across days. We observed monthto-month variability but the relative differences between 
Table 4 Variance component analyses of sitting time, standing time, and time spent on moderate-to-vigorous physical activity (MVPA) per day as well as for total steps per day at work, in leisure time and in total (work and leisure time combined)

\begin{tabular}{|c|c|c|c|c|c|}
\hline$\overline{\text { Model }^{a}}$ & Constant $^{b}$ & $95 \% \mathrm{Cl}$ & $\mathrm{RSD}^{c}$ & $I C C^{d}$ & $\begin{array}{l}\text { Intra-individual } \\
\text { variation }\end{array}$ \\
\hline work sit (min) & 323 & $300-347$ & 0.23 & 0.46 & $54 \%$ \\
\hline $\begin{array}{l}\text { work stand } \\
\text { (min) }\end{array}$ & 102 & $82-121$ & 0.62 & 0.49 & $51 \%$ \\
\hline work steps & 3761 & $3211-4310$ & 0.40 & 0.50 & $50 \%$ \\
\hline $\begin{array}{l}\text { work MVPA } \\
\text { (min) }\end{array}$ & 27 & $22-31$ & 0.43 & 0.49 & $51 \%$ \\
\hline $\begin{array}{l}\text { leisure sit } \\
\text { (min) }\end{array}$ & 282 & $264-300$ & 0.21 & 0.42 & $58 \%$ \\
\hline $\begin{array}{l}\text { leisure stand } \\
\text { (min) }\end{array}$ & 97 & 86-109 & 0.38 & 0.46 & $54 \%$ \\
\hline leisure steps & 5682 & 4919-6446 & 0.48 & 0.37 & $63 \%$ \\
\hline $\begin{array}{l}\text { leisure MVPA } \\
\text { (min) }\end{array}$ & 47 & $40-54$ & 0.52 & 0.41 & $59 \%$ \\
\hline total sit (min) & 606 & $574-637$ & 0.16 & 0.50 & $50 \%$ \\
\hline $\begin{array}{l}\text { total stand } \\
\text { (min) }\end{array}$ & 199 & $173-225$ & 0.39 & 0.57 & $43 \%$ \\
\hline total steps & 9349 & 8357-10340 & 0.34 & 0.43 & $57 \%$ \\
\hline $\begin{array}{l}\text { total MVPA } \\
\text { (min) }\end{array}$ & 73 & $65-81$ & 0.38 & 0.44 & $56 \%$ \\
\hline
\end{tabular}

${ }^{a}$ Multilevel linear regression model with the activity of interest as dependent variable adjusted for sex, age, educational level and BMI

${ }^{\mathrm{b}}$ Constant representing mean value for a male participant aged 45 with tertiary education and a BMI below 25

'Relative standard deviation = standard deviation $/$ mean

dinterclass correlation coefficient: part of total variance explained by difference between individuals

e Percentage of total variance explained by variation within individual

Table 5 Number of measurement days needed for $80 \%, 85 \%$ and $90 \%$ reliability when measuring sitting time and physical activity at work and in leisure time by using a thigh-born accelerometer (Actigraph)

\begin{tabular}{lccc}
\hline & $\begin{array}{l}\text { No. Days, 80\% } \\
\text { reliability }\end{array}$ & $\begin{array}{l}\text { No. Days, 85\% } \\
\text { reliability }\end{array}$ & $\begin{array}{l}\text { No. Days, 90\% } \\
\text { reliability }\end{array}$ \\
\hline Work sit (min) & 4.7 & 6.7 & 10.6 \\
Work stand (min) & 4.2 & 5.9 & 9.4 \\
Work steps & 4.0 & 5.7 & 9.0 \\
Work MVPA (min) & 4.2 & 5.9 & 9.4 \\
Leisure sit (min) & 5.5 & 7.8 & 12.4 \\
Leisure stand (min) & 4.7 & 6.7 & 10.6 \\
Leisure steps & 6.8 & 9.6 & 15.3 \\
Leisure MVPA (min) & 5.8 & 8.2 & 13.0 \\
Total sit (min) & 4.0 & 5.7 & 9.0 \\
Total stand (min) & 3.0 & 4.3 & 6.8 \\
Total steps & 5.3 & 7.5 & 11.9 \\
Total MVPA (min) & 5.1 & 7.2 & 11.5 \\
\hline
\end{tabular}

the periods were small: between 5\% for leisure sitting and $9 \%$ for leisure steps (data not shown). Due to the small relative difference between periods, we included days from all the three periods in the analysis of days needed to measure to obtain a certain level of reliability. The variation between the periods could be due to seasonal differences in e.g. weather and variation in work tasks over the months. Often accelerometers are only worn for a single period of time e.g. 7 days, and our results indicate that inclusion of additional measurement weeks or seasons will add variability and show that more days are needed to reliably estimate activity patterns across a period of time. Few studies have determined the reliability for several periods of measurement over the course of a year, of which all have shown considerable intra-individual variation [10, 26, 27]. However, although an increased monitoring length might improve reliability and consequently the validity of the study conclusions, the burden for study participants and study feasibility also needs to be considered.

\section{Strengths and limitations}

Our study had strengths and limitations. One strength of the study was the use of thigh-born accelerometer that was worn for $24 \mathrm{~h}$ per day, which ensured no bias from difference in wear time. Secondly, by placing the accelerometer on the thigh, we were able to distinguish sitting time from standing or sleeping time. Thirdly, we included a relatively large sample of adults $(n=135)$. The study has limitations as well. Firstly, in the present study, the variability did not vary from day-to-day which has also been shown in other studies $[8,13,25]$. ICC is a relative and context-specific estimate that depends on the heterogeneity of the sample $[28,29]$. The study participants were middle-aged adults with office-based work and variability in physical activity measurements may be different among other age groups or people with other types of jobs or without jobs. A second limitation was that activity measurements were only obtained on workdays; hence, we could not investigate differences in variability between work days and weekend days. In a study among 30 males it was found that habitual physical activity tended to be greater during weekdays compared to weekend days [8] but in a study by Bingham et al. [25] no difference in variance of physical activity was found between weekdays and weekend days and thus, it was not possible to conclude whether weekend days have to be included when estimating habitual physical activity. Thirdly, because no information on intensity was obtained, we could not identify vigorous physical activity from moderate-to-vigorous activity and thereby not elaborate about any possible differences in reliability between the two intensity levels. 
Future studies should seek to verify the current findings of variability across populations and examine variability in sedentary behaviour and physical activity within a measurement period containing both weekdays and weekend days. Variability is a natural part of sedentary behaviour and physical activity and it should not be ignored or avoided because it has important implications for measurement and analysis. Further, it would be interesting to study variability in activity patterns, as well as mean activity across a period, in relation to physical activity and sedentary behaviour research in order to understand what role variability in activity plays in relation to health.

\section{Conclusions}

We examined day-to-day and month-to-month variation in sedentary behaviour and physical activity in an adult population with office-based work. Overall, more measurement days were needed to reliably estimate activity patterns during leisure time compared to working hours, as leisure time activities are more variable than working activities. The more variation in activity patterns, the more days of measurements are needed to get reliable estimates. Also, the results indicate that the variability in sedentary behaviour compared to physical activity depends on the domain of interest. Findings from this study combined with previous knowledge implies that variability in activity patterns are important to regard when designing studies entailing measurements of physical activity and sedentary behaviour in order to get reliable estimates.

\section{Abbreviations}

MVPA: Moderate-to-vigorous physical activity; N: Number of days needed; n: Number of participants

\section{Acknowledgements}

We are grateful to all participants in this study.

\section{Funding}

The work was supported by the University of Southern Denmark and the Tryg Foundation.

\section{Availability of data and materials}

The datasets supporting the conclusions of this article are available upon request to the corresponding author. Due to data protection restrictions and participant confidentiality, we do not make participant data publicly available.

\section{Authors' contributions}

ELP performed the analysis and prepared the manuscript. ELP, CBP and JST designed the analytical strategy and directed its implementation. IHD and CBP were involved with data collection. IHD was involved with data analysis. All authors certify to have participated sufficiently in the work to take public responsibility for the appropriateness of the design, method, collection, analysis and interpretation of the data. Additionally, all authors have read and approved the final version and have agreed to share data used in the study.

\section{Competing interests}

The authors declare that they have no competing interests.
Consent for publication

Not applicable.

\section{Ethics approval and consent to participate}

The trial was approved by the local Ethics Committee in Denmark (H-6-2013005) and in Greenland (project 20914-3, id: 2014-095402). Procedures were designed in accordance with the Helsinki Declaration. At an introductory meeting, the management and an employee representative signed a consent form. Employees were then invited to participate by email and informed about the project in writing and orally, and signed informed consent.

Received: 23 June 2016 Accepted: 29 November 2016

Published online: 03 December 2016

\section{References}

1. Bauman AE. Updating the evidence that physical activity is good for health: an epidemiological review 2000-2003. J Sci Med Sport. 2004;7(1 Suppl):6-19.

2. Lee IM, Shiroma EJ, Lobelo F, Puska P, Blair SN, Katzmarzyk PT. Effect of physical inactivity on major non-communicable diseases worldwide: an analysis of burden of disease and life expectancy. Lancet. 2012;380(9838):219-29.

3. Dunstan DW, Howard B, Healy GN, Owen N. Too much sitting-a health hazard. Diabetes Res Clin Pract. 2012:97(3):368-76.

4. Thorp AA, Owen N, Neuhaus M, Dunstan DW. Sedentary behaviors and subsequent health outcomes in adults a systematic review of longitudinal studies, 1996-2011. Am J Prev Med. 2011;41(2):207-15.

5. Thorp AA, Healy GN, Winkler E, et al. Prolonged sedentary time and physical activity in workplace and non-work contexts: a cross-sectional study of office, customer service and call centre employees. Int J Behav Nutr Phys Act. 2012;9:128.

6. van der Ploeg HP, Moller SV, Hannerz H, van der Beek AJ, Holtermann A. Temporal changes in occupational sitting time in the Danish workforce and associations with all-cause mortality: results from the Danish work environment cohort study. Int J Behav Nutr Phys Act. 2015;12:71.

7. van Uffelen JG, Wong J, Chau JY, et al. Occupational sitting and health risks: a systematic review. Am J Prev Med. 2010;39(4):379-88.

8. Gretebeck RJ, Montoye HJ. Variability of some objective measures of physical activity. Med Sci Sports Exerc. 1992:24(10):1167-72.

9. Jerome GJ, Young DR, Laferriere D, Chen C, Vollmer WM. Reliability of RT3 accelerometers among overweight and obese adults. Med Sci Sports Exerc. 2009;41(1):110-4.

10. Levin S, Jacobs Jr DR, Ainsworth BE, Richardson MT, Leon AS. Intraindividual variation and estimates of usual physical activity. Ann Epidemiol. 1999;9(8):481-8.

11. Matthews CE, Ainsworth BE, Thompson RW, Bassett Jr DR. Sources of variance in daily physical activity levels as measured by an accelerometer. Med Sci Sports Exerc. 2002;34(8):1376-81.

12. Aadland $E$, Ylvisaker $E$. Reliability of objectively measured sedentary time and physical activity in adults. PloS One. 2015:10(7):e0133296.

13. Hart TL, Swartz AM, Cashin SE, Strath SJ. How many days of monitoring predict physical activity and sedentary behaviour in older adults? Int J Behav Nutr Phys Act. 2011;8:62

14. Danquah $\mathbb{I H}$, Kloster $\mathrm{S}$, Holtermann A, et al. Take a Stand!-a multicomponent intervention aimed at reducing sitting time among office workers-a cluster randomized trial. Int J Epidemiol. 2016;1-13

15. Actigraph. 2013. Available from: http://actigraphcorp.com/. Actgraph. Accessed 14 Nov 2015

16. Skotte J, Korshoj M, Kristiansen J, Hanisch C, Holtermann A. Detection of physical activity types using triaxial accelerometers. J Phys Act Health. 2014; 11(1):76-84.

17. Ingebrigtsen J, Stemland I, Christensen C, et al. Validation of a commercial and Custom Made Accelerometer-Based Software for Step Count and Frequency during Walking and Running. J Ergon. 2013;3(2). http://dx.doi. org/10.4172/2165-7556.1000119.

18. Stemland I, Ingebrigtsen J, Christiansen CS, et al. Validity of the Acti4 method for detection of physical activity types in free-living settings: comparison with video analysis. Ergonomics. 2015;58(6):953-65.

19. Baranowski T, Masse LC, Ragan B, Welk G. How many days was that? We're still not sure, but we're asking the question better! Med Sci Sports Exerc. 2008;40(7 Suppl):S544-9.

20. McGraw KO, Wong SP. Forming inferences about some intraclass correlation coefficients. Psychol Methods. 1996;1:30-46. 
21. Trost SG, Mclver KL, Pate RR. Conducting accelerometer-based activity assessments in field-based research. Med Sci Sports Exerc. 2005;37(11 Suppl):S531-43.

22. Autenrieth CS, Baumert J, Baumeister SE, et al. Association between domains of physical activity and all-cause, cardiovascular and cancer mortality. Eur J Epidemiol. 2011;26(2):91-9.

23. Turi BC, Codogno JS, Fernandes RA, Sui X, Lavie CJ, Blair SN, Monteiro HL. Association of Different Physical Activity Domains on All-Cause Mortality in Adults Participating in Primary Care in the Brazilian National Health System: 4-year Follow-up. J Phys Act Health. 2016: 1-22. [Epub ahead of print]

24. Huerta JM, Chirlaque MD, Tormo MJ, et al. Work, household, and leisuretime physical activity and risk of mortality in the EPIC-Spain cohort. Prev Med. 2016;85:106-12.

25. Bingham DD, Costa S, Clemes SA, Routen AC, Moore HJ, Barber SE. Accelerometer data requirements for reliable estimation of habitual physical activity and sedentary time of children during the early years - a worked example following a stepped approach. J Sports Sci. 2016;34(20):2005-10.

26. Mattocks $C$, Leary S, Ness A, et al. Intraindividual variation of objectively measured physical activity in children. Med Sci Sports Exerc. 2007;39(4):622-9.

27. Wickel EE, Welk GJ. Applying generalizability theory to estimate habitual activity levels. Med Sci Sports Exerc. 2010;42(8):1528-34.

28. Bland JM, Altman DG. Statistical methods for assessing agreement between two methods of clinical measurement. Lancet. 1986;1 (8476):307-10.

29. Hopkins WG. Measures of reliability in sports medicine and science. Sports Med. 2000;30(1):1-15.

\section{Submit your next manuscript to BioMed Central} and we will help you at every step:

- We accept pre-submission inquiries

- Our selector tool helps you to find the most relevant journal

- We provide round the clock customer support

- Convenient online submission

- Thorough peer review

- Inclusion in PubMed and all major indexing services

- Maximum visibility for your research

Submit your manuscript at www.biomedcentral.com/submit 